\title{
Feasibility study of using amplified piezo-stack actuators for the actuation of direct drive servovalves
}

\author{
Paolo Tamburrano ${ }^{1 *}$, Pietro De Palma ${ }^{1}$, Andrew R. Plummer ${ }^{2}$, Elia Distaso $^{1}$, and \\ Riccardo Amirante ${ }^{1}$ \\ ${ }^{1}$ Department of Mechanics, Mathematics and Management (DMMM), Polytechnic University of Bari, \\ Bari, 70125, Italy \\ ${ }^{2}$ Centre for Power Transmission and Motion control, University of Bath, Bath, BA2 7AY, UK
}

\begin{abstract}
In this paper, we investigate the idea of using, in place of recent linear force motors, amplified piezo-stack actuators for the actuation of direct drive servovalves, in order to exploit the fast response of piezoelements accompanied by the increased displacement ensured by mechanical amplification systems. Some possible architectures are proposed in this paper for the direct actuation of four-way three-position (4/3) servovalves using one or two commercially available amplified piezo-stack actuators having a diamond amplification mechanism. The simplest architecture, which employs only one actuator, is assessed using wellestablished equations implemented in Simulink, allowing the hydraulic, mechanical and electrical parts of the valve to be accurately simulated. Three spools of different size are considered in the simulations in order to obtain performance predictions for different valve flow ratings. From the analysis of the inherent characteristics of the amplified piezo-stack and from the results of the simulations, advantages and disadvantages of this possible architecture are drawn and discussed in detail. Among the advantages, there are the simplicity of construction and the high potential in terms of step response speed and frequency response; the large dimensions, low chip shear force capability and high costs are the main disadvantages.
\end{abstract}

Keywords: servovalve, direct drive, amplified piezo-stack, Simulink.

\section{Introduction}

Servovalves are widely used components in several industrial and aeronautical applications. The most common architecture is composed of two stages, namely, the pilot stage and the main stage. The pilot stage, which usually employs a double nozzle flapper, a deflector jet or a jet pipe, is driven by a torque motor, providing hydraulic amplification for the main stage, which is usually a spool valve composed of a spool and a bushing sleeve.

${ }^{*}$ Corresponding author: paolo.tamburrano@poliba.it 
This architecture provides several benefits, such as very high actuation forces and fast response speed [1].

Instead of using two stage architectures, some manufacturers like Moog [2] also produce single stage valves using linear force motors to directly move the spool inside its bushing sleeve. Linear force motors are made of rare earth magnets; they have lower moving mass, larger driving forces and better linearity than proportional solenoids, thus having better performance and wider operation ranges [3]. Such a single stage architecture, which is a servovalve because it has a bushing sleeve and is manufactured with fine tolerances, has the disadvantage of having lower actuation forces than two stage servovalves, hence, lower chip shear capability and lower response speed [2]. In addition, a linear force motor, being approximately the same size as the main stage, is much larger and heavier than a torque motor. Compared to a two stage servovalve, a single stage servovalve is therefore less convenient for some applications like aircraft, where the actuation forces and weight are important factors. Instead, for those industrial applications where these factors are less important, a single stage servovalve is an interesting architecture, especially in terms of simplicity of construction, given that the pilot stage and its complex components, such as the torque motor and the flexure tube, are removed. The internal leakage is also reduced, since the pilot stage, which continuously requires quiescent flow, is removed [1].

This paper investigates how a single stage servovalve can directly be driven by piezoelectric actuators instead of linear force motors. In particular, the idea here presented consists in using amplified piezo-stack actuators, which can provide interesting features, such as fast response, typical of piezo-electric elements, and lower weight than electric actuators.

The most common piezo electric actuators available on the market are ring benders, rectangular benders, piezo-stacks, and amplified piezo-stacks [1]. In previous studies, we demonstrated that ring benders and rectangular benders are suitable for the actuation of the pilot stages of servovalves [4-8]. Concerning ring benders, two of them, mounted in tandem to provide redundancy, were proposed in [4] to actuate, in place of the torque motor, a double nozzle flapper pilot stage; the feasibility of this architecture was assessed using a detailed Simulink model of the hydraulic, mechanical and electrical parts [4]. In [5, 6], we proposed and studied a novel pilot stage configuration composed of two normally closed two-way twoposition $(2 / 2)$ valves actuated by two piezo-electric ring benders, achieving very good step and frequency response in addition to minimizing the internal leakage. Again, a Simulink model was instrumental in assessing this novel architecture $[5,6]$; the comparison between the results of the simulations and the experimental data showed that this simulation approach provides very good accuracy [5]. Concerning rectangular benders, there are some examples, provided by us and by other authors, of rectangular benders applied to the actuation of deflector jet pilot stages and to the actuation of double nozzle flapper pilot stages [8-11].

Although the above-mentioned studies proved that ring benders and rectangular benders are suitable for the actuation of the pilot stages of servovalves, they are not appropriate for the direct actuation of a main spool because higher values of actuation forces and displacement are needed for this purpose. Piezo-stacks are quite different from ring benders and rectangular benders, being composed of several piezo-elements joined together to form a multi-layer actuator, thus providing very high actuation forces but small displacement. There are some examples of application to the actuation of the pilot stages of servovalves [12], but the direct actuation of a main spool seems unfeasible also in this case because a very large piezo-stack actuator would be needed for this purpose. Indeed, as a rough estimate, a piezo-stack that is $15 \mathrm{~cm}$ long can produce a maximum free stroke of only $240 \mu \mathrm{m}$ in only one direction [13]; therefore, to obtain a displacement of $500 \mu \mathrm{m}$ in only one direction, a very large piezo-stack (about $30 \mathrm{~cm}$ long) would be needed.

The only piezo actuator that possesses characteristics compatible with the direct actuation of a main spool seems to be the amplified piezo-stack. It is composed of a piezo-stack and an 
amplification system which is adopted to increase the displacement of the piezo-stack [1]. By virtue of the increased displacement, the direct actuation of a main spool can be feasible. In the literature, there are already two experimental studies proposing a servovalve directly driven by an amplified piezo-stack $[14,15]$. In both cases, the amplification mechanism consists of a lever element which is used to amplify the maximum displacement of the piezostack. This valve configuration, despite providing a limited maximum flow rate (around 8 $1 /$ min for an inlet pressure of 40 bar [15]), shows that the concept is viable. In addition, the concept can benefit from novel and effective amplification mechanisms recently realized by some manufacturers, such as the "diamond" structure [13].

In this scenario, a feasibility study of direct drive servovalves actuated by commercially available amplified piezo-stacks having diamond amplification mechanisms is performed for the first time in the present work. Firstly, a few possible configurations, using one or two amplified piezo-stacks, are presented. A Simulink model is then employed to predict the achievable performance of one of these configurations, in terms of maximum displacement and maximum flow rate, step response speed and frequency response, by simulating three different sized spools. Advantages and disadvantages of this architecture, deduced by the simulation results and by the analysis of the characteristics of the amplified piezo-stack, are finally discussed in detail.

\section{Schemes of application of amplified piezo-stacks to direct drive servovalves}

In the schemes analyzed in this section, the amplification mechanism considered for the amplified piezo-stack actuator is that used by the manufacturer Noliac [13], which consists of the diamond structure shown in Fig.1. In this structure, four piezo-stack elements are connected in pairs. In the neutral position, the two pairs form a certain angle with a moving slider. The whole assembly is preloaded through a tension member maintaining the four elements in place. To generate displacement, an amplified voltage (obtained through an amplifier) must properly be applied in order to increase the length of one pair and decrease the length of the other one, as shown in Fig.1. On the website of the manufacturer, it is stated that two mode of operation can be used as far as the amplifier is concerned. It can operate from $-100 \mathrm{~V}$ to $+100 \mathrm{~V}$, the negative values moving the slider to the left and the positive values moving the slider to the right. Alternatively, it can operate from 0 to $+200 \mathrm{~V}$, the values less than $+100 \mathrm{~V}$ moving the slider to the left and the values greater than $+100 \mathrm{~V}$ moving the slider to the right.

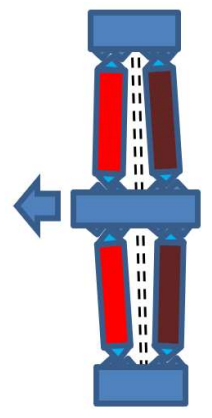

Pull

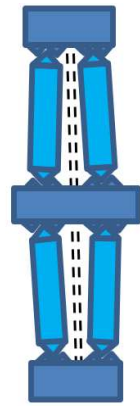

Neutral position

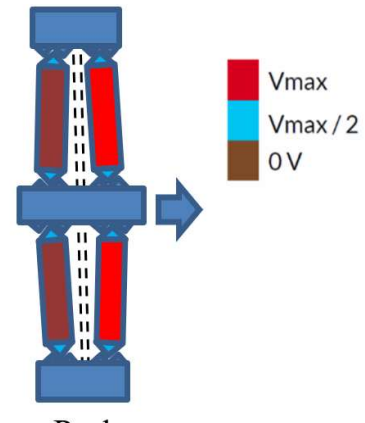

Push

Fig. 1. Operating principle of an amplified stack actuator with diamond structure [13] 
According to Noliac, this architecture can push and pull with the same level of performance and is temperature stable [13]. Indeed, changes in the operating temperature will be compensated by the internal preload, thus preventing the movement of the slider from the neutral position [13].

Noliac produces three amplified piezo-stacks having this amplification mechanism, with a price of the order of 2000 Euros. They have different characteristics in terms of maximum free stroke, maximum blocking force, stiffness and dimensions. Their specifications are reported in Table 1.

Table 1. Amplified stack actuators produced by Noliac: specifications [13]

\begin{tabular}{|c|c|c|c|c|c|}
\hline Parameter & Unit & NAC2641 & NAC2643 & NAC2645 & Tolerances \\
\hline Width & $\mathrm{mm}$ & 14 & 14 & 14 & \pm 0.1 \\
\hline Length & $\mathrm{mm}$ & 70.5 & 102.4 & 134.2 & \pm 0.1 \\
\hline Height & $\mathrm{mm}$ & 26.1 & 28 & 30.6 & \pm 0.3 \\
\hline $\begin{array}{l}\text { Max. free stroke (working in } \\
\text { one direction), } x_{\max }\end{array}$ & $\mu \mathrm{m}$ & 300 & 625 & 950 & $\pm 15 \%$ \\
\hline $\begin{array}{l}\text { Max. free stroke (working in } \\
\text { two directions), } x_{\max }\end{array}$ & $\mu \mathrm{m}$ & \pm 150 & \pm 312.5 & \pm 475 & $\pm 15 \%$ \\
\hline Stiffness, $k_{p}$ & $\mathrm{~N} / \mu \mathrm{m}$ & 1.3 & 0.9 & 0.7 & $\pm 15 \%$ \\
\hline Max. blocking force, $F_{b, \max }$ & $\mathrm{N}$ & 195 & 281 & 332 & $\pm 15 \%$ \\
\hline $\begin{array}{l}\text { Max. actuation force at } 20^{\circ} \mathrm{C}, \\
F_{a c t, \max }\end{array}$ & $\mathrm{N}$ & 250 & 250 & 250 & - \\
\hline $\begin{array}{l}\text { Max. actuation force at } 50{ }^{\circ} \mathrm{C}, \\
F_{a c t, \max }\end{array}$ & $\mathrm{N}$ & 200 & 200 & 200 & - \\
\hline Mass, $m_{p}$ & $\mathrm{~g}$ & $84+60$ (cable) & $122+60$ (cable) & $160+60($ cable $)$ & $\pm 10 \%$ \\
\hline Capacitance, Cap & $\mu \mathrm{F}$ & $2 \times 3.6$ & $2 \times 6.5$ & $2 \times 10$ & \\
\hline
\end{tabular}

For all the three models, the actuation force $F_{a c t}$ is given by the blocking force $F_{b}$ minus the elastic force that is generated internally by the stiffness of the amplified piezo-stack. The blocking force is proportional to the amplified voltage applied to the actuator, the maximum blocking force $F_{b, \max }$ being obtained for the maximum voltage. The maximum free stroke $x_{\max }$ is the maximum displacement obtained for a null actuation force, namely, when no load is applied. If the amplified piezo-stack works in both directions (push and pull mode), the maximum free stroke is one half of that obtained when the amplified piezo-stack works in one direction only (either push or pull mode). In the case of a push and pull mode of operation, the maximum free stroke provided by model NAC2645 is $\pm 0.475 \mathrm{~mm}$, which is very similar to the displacement obtained by a linear force motor (about $\pm 0.5 \mathrm{~mm}$ [1]). Therefore, the values of the displacement are compatible with the direct actuation of a spool valve.

The amplified piezo-stacks produced by Noliac have an operation limit concerning the maximum actuation force, which is $F_{a c t, \max }=250 \mathrm{~N}$ at $20{ }^{\circ} \mathrm{C}$ and $F_{a c t, \text { max }}=200 \mathrm{~N}$ at $50{ }^{\circ} \mathrm{C}$. According to the manufacturer's instructions, if the amplified piezo-stack pushes or pulls with a greater force than this limit, the internal components may become loose and shift, thus hindering the correct operation of the mechanism. This force limit changes with the 
temperature because differential thermal expansions between the ceramic and the other materials in the assembly will lead to a change in the internal preload. However, the maximum actuation force is sufficiently high to win the opposing forces in a spool valve, namely, the flow forces and friction. Nonetheless, this limitation for the maximum actuation force is a disadvantage as far as the chip shear capability is concerned, since the force necessary to shear contamination particles that can be caught between the edges of a metering section can exceed $200 \mathrm{~N}$.

Table 1 shows that the three amplified piezo-stack actuators are particularly large, especially NAC2645, which is the model more compatible with the direct actuation of a servovalve. In terms of dimensions, this is a disadvantage compared to linear force motors, which are more compact. However, the overall weight of model NAC2645 is only $160 \mathrm{~g}$, thus being lighter than electric actuators.

A first scheme of application of the amplified piezo-stack to the actuation of a spool valve is shown in Fig. 2(a). The valve considered is a four-way three-position (4/3) valve, being the most used in industry [1]. In the proposed configuration, the slider of the amplified piezostack moves the spool in both directions. Therefore, if the slider is moved to the left, the fluid can flow from port $\mathrm{P}$ to port $\mathrm{A}$ and from port $\mathrm{B}$ to port $\mathrm{T}$; if the slider is moved to the right, the fluid can flow from port $\mathrm{P}$ to port B and from port A to port T. Large slots must be used to achieve flow metering over a limited spool stroke. A linear variable differential transformer (LVDT) is needed to compensate for hysteresis and to achieve closed loop control. Note that the case of the amplified piezo-stack will be filled with oil, therefore a damping effect will be generated due to the oil being displaced inside the case. Therefore, the geometry of the case will affect the damping factor of the amplified piezo-stack.

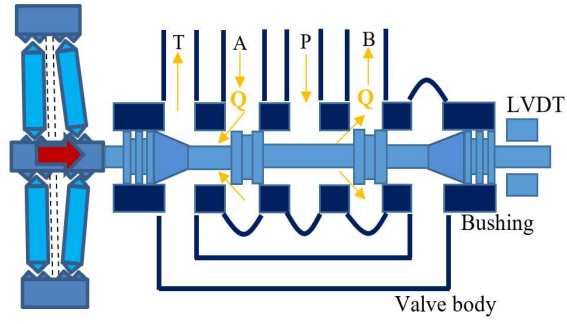

(a)

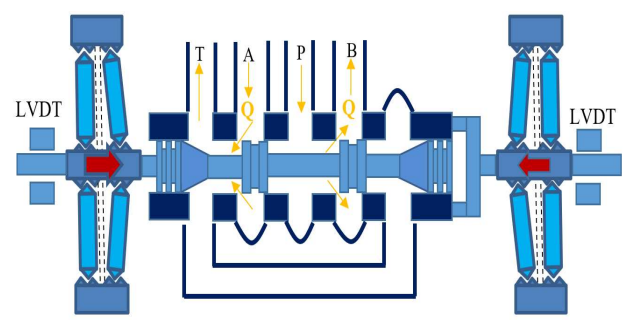

(c)

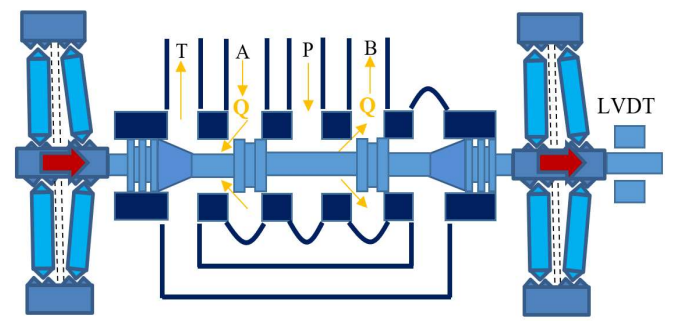

(b)

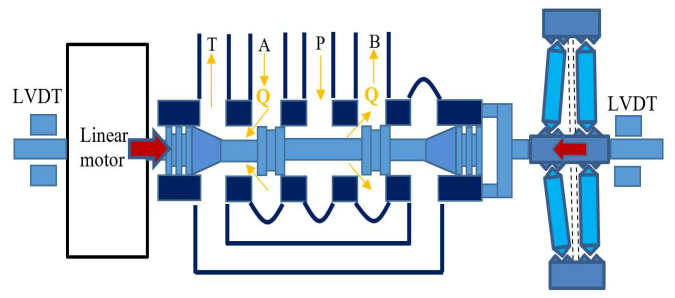

(d)

Fig. 2. Four schemes of application of amplified piezo-stack actuators to direct drive servovalves

As an alternative scheme, two amplified stack actuators can be used to move the spool simultaneously to provide higher force, as shown in Fig. 2(b). Indeed, in this scheme, the left actuator can work in push mode and the right actuator in pull mode (or viceversa). This 
architecture would be particularly effective in aerospace applications in case of failure of one of the two piezo-actuators. An LVDT is again needed to compensate for hysteresis.

A third possible scheme of application is shown in Fig. 2(c). An amplified stack actuator moves the spool and another one moves the bushing sleeve. In this case, the overall displacement is determined by the two actuators; therefore, the maximum opening degree is twice that of the scheme of Fig. 2(a). Two LVDTs are needed to compensate for hysteresis and to achieve closed loop control.

A final scheme is depicted in Fig. 2(d). An amplified stack actuator is used to improve the dynamic of a linear force motor valve. In this case, the piezo-actuator can be used to move the bushing sleeve. Two LVDTs are needed in this final scheme as well.

\section{Numerical model}

The performance of the simplest architecture proposed, namely, that shown in Fig. 2(a), is assessed using well-established equations implemented in Simulink through the libraries of Simscape Fluids [16]. As mentioned in the introduction, we already used a similar numerical approach to study a novel low leakage two stage servovalve actuated by ring benders $[5,6]$; moreover, a comparison between the results of the simulations and experimental data was performed in [5], revealing great accuracy of this numerical approach.

The equations implemented in Simulink are described in the following, with reference to the spool moving only from the left to the right for the sake of simplicity, as shown in Fig. 3.

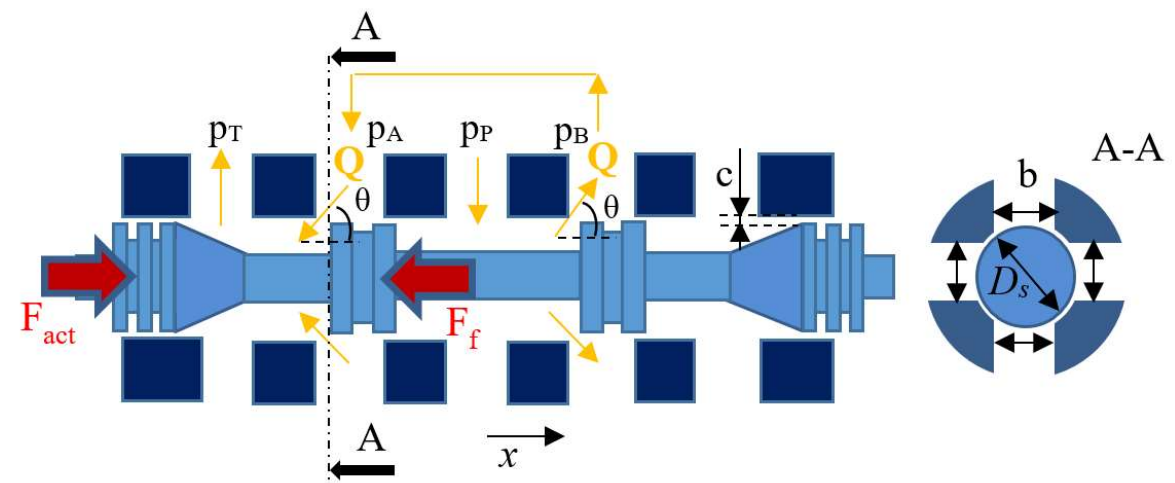

Fig. 3. Sketch including the main parameters used in the numerical model (the clearance $c$ is overestimated for the sake of clarity)

A relationship exists between the actuation force developed by the amplified piezo-stack $\left(F_{a c t}\right)$ and its displacement $(x)$. Fig. 4 shows that, in the $x-F_{\text {act }}$ plane, it is a straight line with a certain slope which translates along the horizontal axis as a function of the amplified voltage applied to the piezo-stack $\left(V_{a m p}\right)$. This behavior is due to the amplified piezo-stack working as a spring having a stiffness $k_{p}$, which causes the actuation force to depend on the displacement of the amplified piezo-stack, as follows:

$$
F_{a c t}=F_{b}-k_{p} x
$$

where $F_{b}$ is the blocking force; $F_{b}$ increases with $V_{a m p}$, thus, the maximum blocking force $F_{b, \max }$ is obtained for $V_{a m p}=V_{\max }, V_{\max }$ being the maximum voltage. The horizontal line $F_{a c t}=F_{a c t \text { max }}$ in Fig. 4 denotes the maximum operation field of the amplified piezo-stack; as explained before, the manufacturer advises against exceeding $F_{\text {act,max }}$.

The maximum free stroke $x_{\max }$ is the maximum displacement of the amplified piezo-stack, which is obtained for a null actuation force; therefore, $x_{\max }$ is obtained by applying $F_{a c t}=0$, 
$F_{b}=F_{b, \max }$, and $x=x_{\max }$ in equation (1). The stiffness $k_{p}$ is the ratio between $F_{b, \max }$ and $x_{\max }$ :

$$
k_{p}=\frac{F_{b, \max }}{x_{\max }} .
$$

The blocking force depends on the amplified voltage $V_{a m p}$ as follows:

$$
F_{b}=K_{V F} V_{a m p},
$$

where $K_{V F}$ is a conversion factor (from voltage to force).

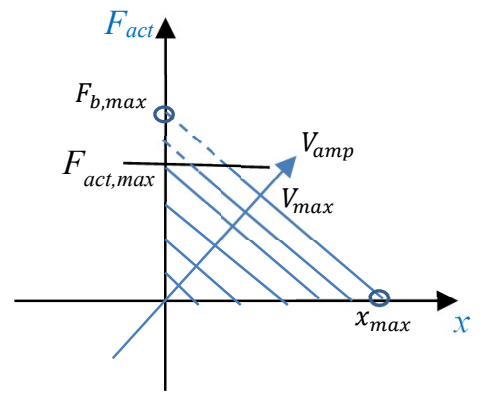

Fig. 4. Actuation force-displacement relationship for an amplified piezo-stack

The equilibrium of the forces acting on the spool can be written as follows:

$$
F_{a c t}-F_{f}-\left(C_{p}+C_{s}\right) \dot{x}-\left(m_{p}+m_{s}\right) \ddot{x}=0,
$$

where $x$ is the displacement of the spool, which is equal to the displacement of the amplified piezo-stack; $F_{f}$ is the flow force acting on the spool; $C_{p}$ and $C_{s}$ are the damping factors of the amplified piezo-stack and of the spool, respectively; $m_{p}$ and $m_{s}$ respectively denote the mass of the moving parts of the amplified piezo-stack and the mass of the spool. To evaluate the damping factor of the spool, which is due to the frictional forces acting on the spool, the following relation can be used [17]:

$$
C_{s}=\frac{\mu \pi D_{s} l_{s}}{c \sqrt{\left(1-\left(\frac{\varepsilon}{c}\right)^{2}\right.}},
$$

where $\mu$ is the dynamic viscosity, $D_{s}$ and $l_{s}$ are the diameter and length of the spool, respectively; $c$ is the radial clearance and $\varepsilon$ is the radial eccentricity.

The flow force is calculated by using the following equation $[4,6,18]$ :

$$
F_{f}=2 \rho \frac{Q^{2}}{A_{r, s}} \cos \theta
$$

where the factor 2 considers two metering chambers being opened simultaneously, $\rho$ is the oil density, $Q$ is the volumetric flow rate, $\theta$ is the velocity angle with respect to the horizontal direction; $A_{r, s}$ is the restriction area through each metering chamber, calculated as follows:

$$
\begin{gathered}
A_{r, s}=b x \text { if } x \geq c, \\
A_{r, s}=A_{l, s}=b c \text { if } x<c,
\end{gathered}
$$

where $b$ is the overall slot width, and $A_{l, s}$ is the spool leakage area $[19,20]$.

The flow rate through each metering section of the main stage is calculated using the orifice equation [18]:

$$
Q=C_{D} A_{r, s} \sqrt{\frac{2 \Delta p}{\rho}}
$$


where $C_{D}$ is the discharge coefficient and $\Delta p$ is the pressure drop across the restriction area $A_{r, s}$. In the model, port $\mathrm{A}$ and port $\mathrm{B}$ are hydraulically connected and the pressure drop $p_{B}-$ $p_{A}$ is neglected. Therefore, the pressure drop in equation (8) becomes: $\Delta p=p_{A}-p_{T}=p_{P}-$ $p_{B}=\left(p_{P}-p_{T}\right) / 2$.

The amplified piezo-stack needs an amplifier that must transform a low input control voltage $V_{c}$ into a high output voltage $V_{a m p}$. The relation between the output and the input voltage is simulated by using a second order transfer function $G(s)$ [4]:

$$
G(s)=\frac{K_{a} \omega_{n}^{2}}{s^{2}+2 \xi \omega_{n} s+\omega_{n}^{2}},
$$

where $s$ is the complex variable, while $K_{a}, \omega_{n}$ and $\xi$ are the gain, natural frequency and damping factor of the amplifier. The current limit of the amplifier $I_{\max }$ is computed as follows:

$$
\frac{d V_{a m p}}{d t}=\frac{I_{\max }}{C a p}
$$

where Cap is the capacitance. The hysteresis is not considered because there are no experimental data available to validate a hysteresis model of the amplified piezo-stack.

\section{Results}

The numerical model described in Section 3 is used to simulate the architecture shown in Fig. 2(a).Three sliding spools are considered in order to predict the behavior of a small, a medium and a large valve, the first spool having a diameter of $5 \mathrm{~mm}$ and a mass of $10 \mathrm{~g}$, the second one having a diameter of $10 \mathrm{~mm}$ and a mass of $20 \mathrm{~g}$, and the third one having a diameter of $15 \mathrm{~mm}$ and a mass of $30 \mathrm{~g}$. As explained earlier, the slot width $b$ must be taken large in order to compensate for the small spool displacement. In this analysis, $b$ is taken as equal to $2 / 3$ of the whole perimeter of the spool, thus leading to $b=10.47 \mathrm{~mm}$ for spool $1, b=20.94 \mathrm{~mm}$ for spool 2 and $b=31.42 \mathrm{~mm}$ for spool 3. The clearance is assumed to be $c=3 \mu \mathrm{m}$, being a typical value of servovalves [19]. Using equation (7b), the leakage area is $A_{l, s}=0.03142 \mathrm{~mm}^{2}$ for spool 1, $A_{l, s}=0.06283 \mathrm{~mm}^{2}$ for spool 2 and $A_{l, s}=0.09425 \mathrm{~mm}^{2}$ for spool 3 .

The oil is assumed to be ISO VG 32 at $50{ }^{\circ} \mathrm{C}$, thus having a density equal to $\rho=851 \mathrm{~kg} / \mathrm{m}^{3}$ and a viscosity equal to $\mu=0.0187 \mathrm{~kg} /(\mathrm{m} \mathrm{s})$. The inlet pressure is taken as equal to $70 \mathrm{bar}$, with 1 bar being the discharge pressure.

With regard to the damping factor of the spool, its order of magnitude is calculated using equation (5). Assuming a spool length equal to $l_{s}=50 \mathrm{~mm}$ and an eccentricity during operation equal to $\varepsilon=1 \mu \mathrm{m}$, equation (5) leads to $C_{s}=5.193 \mathrm{Ns} / \mathrm{m}$ for spool $1, C_{s}=10.38 \mathrm{Ns} / \mathrm{m}$ for spool 2 and $C_{s}=15.58 \mathrm{Ns} / \mathrm{m}$ for spool 3. Considering that the length of the spool can change depending on the design adopted by the manufacturer and that the value of the eccentricity cannot be known with precision, only the order of magnitude is significative from this calculation; therefore, the damping factor is assumed to be $C_{s}=10 \mathrm{Ns} / \mathrm{m}$ for all the three spools.

Concerning the discharge coefficient, this parameter depends on the Reynolds number in the metering chamber and on the spool position. However, for turbulent flows, the discharge coefficient in servovalves assumes constant values ranging from 0.65 to 0.7 regardless of the spool position $[18,21]$, unlike the discharge coefficient in proportional valves which can have different values even for turbulent flows depending on the notch geometry and on the spool position $[3,22]$. The flow in the metering chamber of a servovalve is laminar only for very low values of the Reynolds number, usually for $\operatorname{Re}<200 \div 400$ [18, 21]; therefore, for simplicity, the discharge coefficient is assumed to be constant and equal to $C_{D}=0.7$ over the full stroke. This assumption introduces an error only at the very small opening degrees. Concerning the flow angle, its value was experimentally and numerically estimated to be 69 
deg for turbulent flows in servovalves $[18,21,23]$. Therefore, $\theta=69 \mathrm{deg}$ is imposed in equation (6) to calculate the flow forces.

Table 2. Simulation parameters assumed for spool 1, spool 2 and spool 3.

\begin{tabular}{|c|c|c|c|c|c|}
\hline Parameter & Symbol & Unit & $\begin{array}{l}\text { Spool } 1 \\
\text { (value) }\end{array}$ & $\begin{array}{l}\text { Spool } 2 \\
\text { (value) }\end{array}$ & $\begin{array}{l}\text { Spool } 3 \\
\text { (value) }\end{array}$ \\
\hline Main spool diameter & $\overline{D_{s}}$ & $\mathrm{~mm}$ & 5 & 10 & 15 \\
\hline Width of the slots & $b$ & $\mathrm{~mm}$ & 10.47 & 20.94 & 31.42 \\
\hline Main spool mass & $m_{s}$ & $\mathrm{~g}$ & 10 & 20 & 30 \\
\hline $\begin{array}{l}\text { Spool damping } \\
\text { coefficient }\end{array}$ & $\overline{C_{s}}$ & $\mathrm{Ns} / \mathrm{m}$ & 10 & 10 & 10 \\
\hline Clearance & $c$ & $\mu \mathrm{m}$ & 3 & 3 & 3 \\
\hline Leakage area & $A_{l, s}$ & $\mathrm{~mm}^{2}$ & 0.03142 & 0.06283 & 0.09425 \\
\hline Discharge coefficient & $\overline{C_{D}}$ & - & 0.7 & 0.7 & 0.7 \\
\hline Flow angle & $\theta$ & deg & 69 & 69 & 69 \\
\hline Inlet pressure & $p_{p}$ & bar & 70 & 70 & 70 \\
\hline Outlet pressure & $p_{T}$ & bar & 1 & 1 & 1 \\
\hline $\begin{array}{c}\text { Oil density } \\
\left(\text { ISO VG } 32 \text { at } 50^{\circ} \mathrm{C} \text { ) }\right.\end{array}$ & $\rho$ & $\mathrm{kg} / \mathrm{m}^{3}$ & 851 & 851 & 851 \\
\hline $\begin{array}{l}\text { Max. free stroke of the } \\
\text { piezo-actuator }\end{array}$ & $x_{\max }$ & $\mu \mathrm{m}$ & \pm 475 & \pm 475 & \pm 475 \\
\hline $\begin{array}{l}\text { Max. blocking force of } \\
\text { the piezo-actuator }\end{array}$ & $F_{b, \max }$ & $\mathrm{N}$ & 332 & 332 & 332 \\
\hline $\begin{array}{c}\text { Max. actuation force of } \\
\text { the piezo-actuator } \\
\text { (at } 50^{\circ} \mathrm{C} \text { ) }\end{array}$ & $F_{a c t, \max }$ & $\mathrm{N}$ & 200 & 200 & 200 \\
\hline $\begin{array}{l}\text { Stiffness of the piezo- } \\
\text { actuator }\end{array}$ & $K_{p}$ & $\mathrm{~N} / \mathrm{m}$ & 700000 & 700000 & 700000 \\
\hline $\begin{array}{l}\text { Conversion factor (from } \\
\text { voltage to force) }\end{array}$ & $K_{V F}$ & $\mathrm{~N} / \mathrm{V}$ & 3.32 & 3.32 & 3.32 \\
\hline $\begin{array}{l}\text { Natural frequency of the } \\
\text { amplifier }\end{array}$ & $\omega_{n}$ & $\mathrm{rad} / \mathrm{s}$ & 1400 & 1400 & 1400 \\
\hline $\begin{array}{l}\text { Damping factor of the } \\
\text { amplifier }\end{array}$ & $\xi$ & - & 1.5 & 1.5 & 1.5 \\
\hline $\begin{array}{l}\text { Maximum current of the } \\
\text { amplifier }\end{array}$ & $I_{\max }$ & A & 1 & 1 & 1 \\
\hline Capacitance & Cap & $\mu \mathrm{F}$ & $2 \times 10$ & $2 \times 10$ & $2 \times 10$ \\
\hline Gain of the amplifier & $K_{a}$ & - & 20 & 20 & 20 \\
\hline $\begin{array}{l}\text { Maximum amplified } \\
\text { voltage }\end{array}$ & $V_{\max }$ & $\mathrm{V}$ & 100 & 100 & 100 \\
\hline
\end{tabular}

With regard to the amplified piezo-stack, the selected model is NAC2645, being that with the highest free stroke. The maximum free stroke (working in two directions) is $x_{\max }= \pm 475$ $\mu \mathrm{m}$, with a maximum blocking force $F_{b, \max }=332 \mathrm{~N}$. As explained before, the actuation force must not exceed $F_{a c t, \text { max }}=200 \mathrm{~N}$ for a temperature of $50{ }^{\circ} \mathrm{C}$. The stiffness of model NAC2 645 is $k_{p}=700000 \mathrm{~N} / \mathrm{m}$. 
Concerning the amplifier, the manufacturer specifies that different amplifiers can be used to amplify the control signal. It is assumed that the amplifier operates from $-100 \mathrm{~V}$ to $+100 \mathrm{~V}$, the negative values moving the slider to the left and the positive values moving the slider to the right. The amplifier employed in previous studies can be used for this task $[5,6]$. The values of the natural frequency $\omega_{n}$ and of the damping factor $\xi$ are those experimentally retrieved in [5], namely, $\omega_{n}=1400 \mathrm{rad} / \mathrm{s}$ and $\xi=1.5$. The maximum current and the gain of the amplifier are $I_{\max }=1 \mathrm{~A}$ and $K_{\mathrm{a}}=20$ (thus, the control voltage $V_{c}$ is comprised between $-5 \mathrm{~V}$ and $+5 \mathrm{~V})$. The capacitance of the amplified stack is $C a p=2 \times 10 \mu \mathrm{F}$.

All these parameters are reported in Table 2 for completeness.

Firstly, simulations are obtained for spool 1, spool 2 and spool 3 using the parameters of Table 2 and considering four values of the damping factor of the amplified piezo-stack, namely $C_{p}=10,50,100,150 \mathrm{Ns} / \mathrm{m}$. This parameter is not known in advance, depending on the geometry of the case of the amplified piezo-stack, which affects how the oil is displaced inside the case during the slider motion. Therefore, a parametric analysis is performed using four values of the damping factor, with the idea that it is possible to obtain these values by adjusting the geometry of the case.

The mass of the moving parts of the amplified piezo-stack $m_{p}$ is assumed to be one half of the overall mass of the amplified piezo-stack. The overall mass of the amplified piezostack comprising the case (which should be the heaviest part, being realized in stainless steel [13]) is $160 \mathrm{~g}$; therefore, $m_{p}$ is taken as equal to $80 \mathrm{~g}$.

With this parameter setting, Figures 5, 6 and 7 show the time histories of the spool position respectively obtained for spool 1, spool 2 and spool 3 when the control voltage is changed from 0 to $+5 \mathrm{~V}$. A curve is plotted for each of the damping factors assumed for the amplified piezo-stack $C_{p}$. Enlargements of the curves of the flow rate $Q$ and of the actuation force $F_{\text {act }}$ are also provided.

All the curves of the displacement and of the flow rate show some oscillations, which are quite large for $C_{p}=10 \mathrm{Ns} / \mathrm{m}$. Notably, the increase in $C_{p}$ reduces the amplitudes of these oscillations, which become negligible for $C_{p}=100 \mathrm{Ns} / \mathrm{m}$. Therefore, the response is very good for high values of $C_{p}$, with less than $10 \mathrm{~ms}$ being predicted on average to reach the stable condition. Instead, the response for low values of $C_{p}$ is unsatisfactory, the output taking too long to reach a stable condition because of the large oscillations. This suggests that, if the case of the amplified piezo-stack produces low values of the damping factor, changes must be made to the case in order to increase the damping factor.

The maximum displacement and flow rate obtained in the steady state condition for the maximum control voltage are $x=0.4579 \mathrm{~mm}$ and $Q=18.021 / \mathrm{min}$ for spool $1, x=0.4427 \mathrm{~mm}$ and $Q=34.82 \mathrm{l} / \mathrm{min}$ for spool 2, and $x=0.4285 \mathrm{~mm}$ and $Q=50.56 \mathrm{l} / \mathrm{min}$ for spool 3 . As expected, spool 3 provides the highest flow rate because it is paired with the largest slots. For the same reason, spool 2 provides a higher flow rate than spool 1. The opposite occurs for the displacement, the highest value of the displacement being obtained by spool 1 and the lowest by spool 3. This is due to the fact that the flow force increases with the flow rate, thus being the lowest for spool 1 and the highest for spool 3.

Concerning the actuation force, calculated as the difference between the blocking force $\left(F_{b}\right)$ and the internal spring force $\left(k_{p} x\right)$, the graphs reveal that the maximum value imposed by the manufacturer $\left(F_{a c t, \max }=200 \mathrm{~N}\right.$ at $\left.50{ }^{\circ} \mathrm{C}\right)$, is never reached. This is due to the fact that the blocking force has the same trend as the curve of the amplified voltage (red curve), and the maximum blocking force $\left(F_{b, \max }=332 \mathrm{~N}\right)$ is obtained when $V_{a m p}=+100 \mathrm{~V}$. Because of the time interval taken by the amplifier to transform $+5 \mathrm{~V}$ into $+100 \mathrm{~V}$, the maximum blocking force is obtained approximately in correspondence of the maximum opening, when the elastic force is maximum; as a result, the actuation force is always well below $200 \mathrm{~N}$. Notably, all the curves of the actuation force present a drop at about $2 \mathrm{~ms}$, which is particularly significant 
for low values of the damping factor. This is due to the internal spring force, which exceeds the blocking force for a brief instant.

The graphs of Figures 5, 6 and 7 are obtained for a moving mass of the amplified piezostack assumed equal to $m_{p}=80 \mathrm{~g}$ and for different values of the damping factor $C_{p}$. Instead, in order to evaluate the effects of the mass of the moving parts of the amplified piezo-stack, Fig. 8 provides the step response simulated for spool 3 obtained for a fixed value of the damping factor, namely $C_{p}=100 \mathrm{Ns} / \mathrm{m}$, and for different values of the moving mass, namely $m_{p}=80$, $130,180,230 \mathrm{~g}$. The parameters of Table 2 are again used in this simulation. The graphs of Fig. 8 reveal that the mass of the moving part $m_{p}$ has a significant effect on the stability of the response, showing that a mass increase causes a corresponding increase in the oscillations of the spool position. Therefore, in addition to increasing $C_{p}$, it is crucial to decrease $m_{p}$ in order to improve the transient response of the valve.

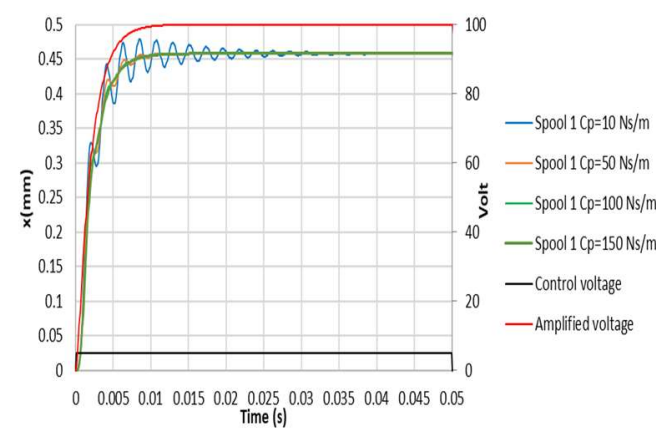

(a)

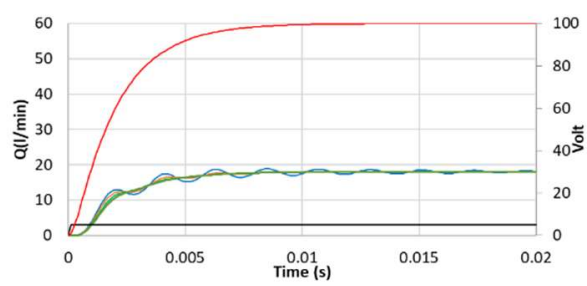

(b)

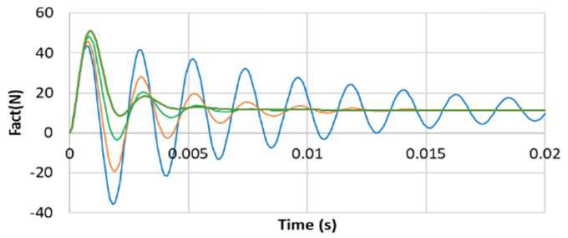

(c)

Fig. 5. Simulated step response for spool $1\left(m_{p}=80 \mathrm{~g}\right)$ and for different values of the amplified piezostack damping factor $\left(C_{p}=10,50,100,150 \mathrm{Ns} / \mathrm{m}\right)$ : time history of the spool position (a), flow rate (b) and actuation force (c)

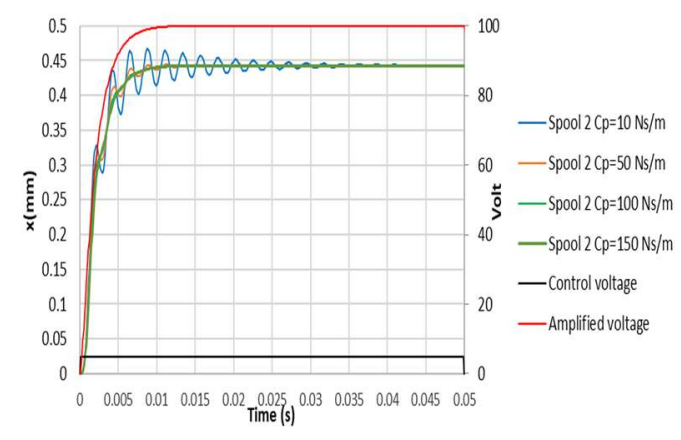

(a)

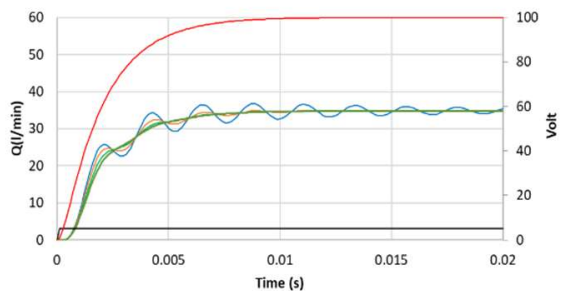

(b)

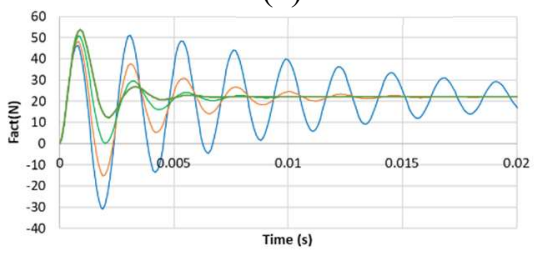

(c)

Fig. 6. Simulated step response for spool $2\left(m_{p}=80 \mathrm{~g}\right)$ and for different values of the amplified piezostack damping factor $\left(C_{p}=10,50,100,150 \mathrm{Ns} / \mathrm{m}\right)$ : time history of the spool position (a), flow rate (b) and actuation force (c) 


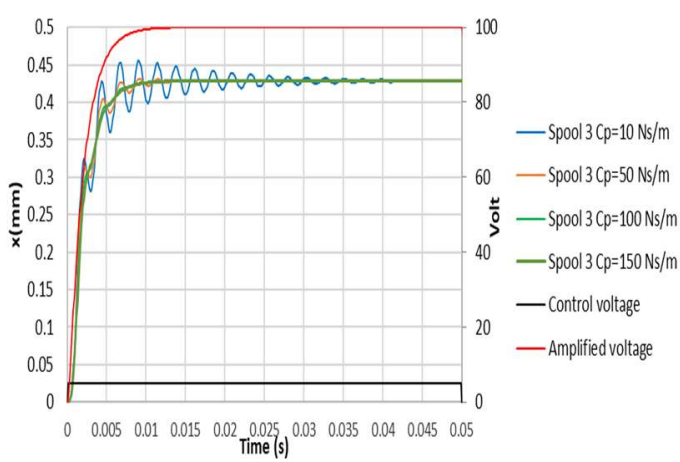

(a)

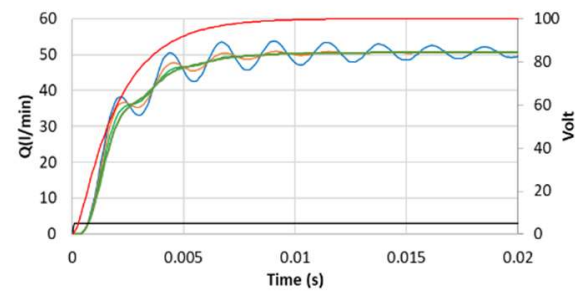

(b)

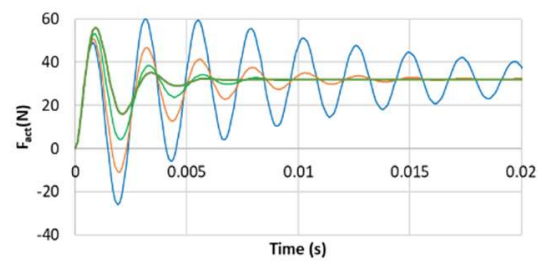

(c)

Fig. 7. Simulated step response for spool $3\left(m_{p}=80 \mathrm{~g}\right)$ and for different values of the amplified piezostack damping factor $\left(C_{p}=10,50,100,150 \mathrm{Ns} / \mathrm{m}\right)$ : time history of the spool position (a), flow rate (b) and actuation force (c)

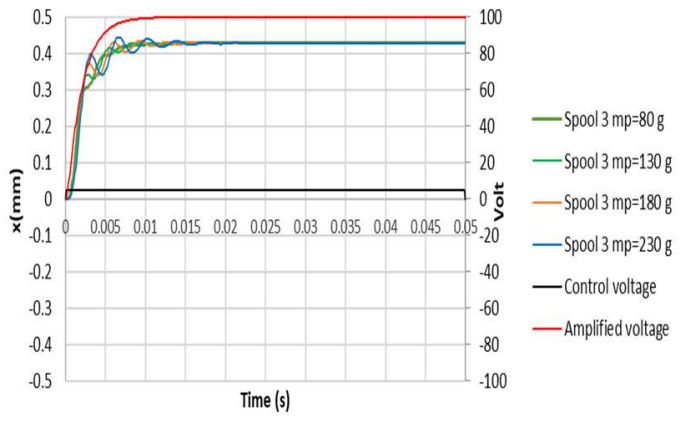

(a)

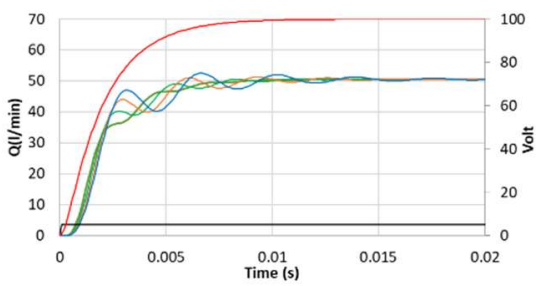

(b)

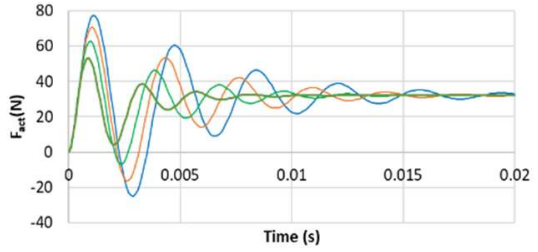

(c)

Fig. 8. Simulated step response for spool $3\left(C_{p}=100 \mathrm{Ns} / \mathrm{m}\right)$ and for different values of the moving mass of the amplified piezo-stack $\left(m_{p}=80,130,180,230 \mathrm{~g}\right)$ : time history of the spool position (a), flow rate (b) and actuation force (c)

The prediction of sinusoidal responses is finally presented. Figures 9(a) and 9(b) show the time history of the position of spool 3 , predicted for a sine control voltage having a frequency of $50 \mathrm{~Hz}$ and $100 \mathrm{~Hz}$, respectively. The amplitude is $2.5 \mathrm{~V}$ in both cases. A fixed value of the damping factor, namely $C_{p}=100 \mathrm{Ns} / \mathrm{m}$, and a fixed value of the mass of the moving parts, namely $m_{p}=80 \mathrm{~g}$, are assumed in the simulations. The frequency response is very good, with a predicted phase shift of $40 \mathrm{deg}$ at $50 \mathrm{~Hz}$ and $70 \mathrm{deg}$ at $100 \mathrm{~Hz}$. 


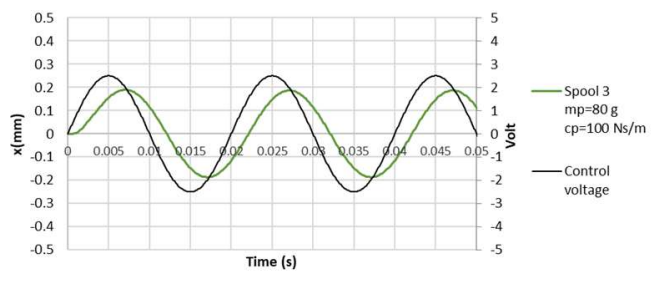

(a)

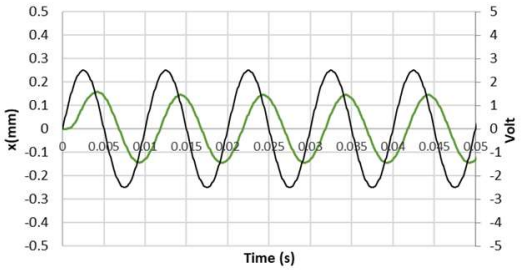

(b)

Fig. 9. Simulated sine response for spool $3\left(C_{p}=100 \mathrm{Ns} / \mathrm{m}, m_{p}=80 \mathrm{~g}\right)$ : input control voltage having a frequency of $50 \mathrm{~Hz}$ and an amplitude of $2.5 \mathrm{~V}$ (a), input control voltage having a frequency of $100 \mathrm{~Hz}$ and an amplitude of $2.5 \mathrm{~V}(\mathrm{~b})$

\section{Conclusions}

This paper investigated the possibility of using commercially available amplified piezo-stack actuators with diamond structure for the actuation of direct drive servovalves. Different schemes of application employing one or two amplified piezo-stacks were proposed. The simplest architecture, in which one amplified piezo-stack actuator pushes and pulls the spool inside its bushing sleeve, was simulated using a Simulink model. The selected amplified piezo-stack actuator was model NAC2645 produced by Noliac, and three spools of different dimensions were simulated. This simulation study, along with the analysis of the characteristics of the amplified piezo stack, allowed the advantages and disadvantages of this architecture to be drawn.

The positive aspects can be summarised as follows:

- The architecture of the proposed configuration is very simple, since the amplified piezostack can directly be attached to the spool.

- The amplified piezo-stacks are lighter than electric actuators, model NAC2645 weighing only $160 \mathrm{~g}$.

- The simulations showed that the amplified piezo-stack can actuate both small spools and larger ones, providing sufficient levels of displacement.

- The actuation forces are sufficient to win the opposing forces of spool valves (friction and flow forces), obtaining a decent operation field (a flow rate of 50 1/min at 70 bar was predicted for the large spool).

- The simulations showed that, if the damping factor of the amplified piezo-stack actuator is high (i.e., greater than $50 \mathrm{Ns} / \mathrm{m}$ ) and the mass of the moving parts of the amplified piezo-stack actuator is sufficiently small (i.e., $80 \mathrm{~g}$ ), the piezoelectric actuation can guarantee fast step response without oscillations (with less than $10 \mathrm{~ms}$ being predicted to stably reach the maximum opening) and very good frequency response (a phase shift of $70 \mathrm{deg}$ was predicted for an input sine control voltage of $100 \mathrm{~Hz}$ ).

- Thanks to the diamond structure, temperature changes in the oil will not cause an undesired movement of the slider of the amplified piezo-stack, and hence of the spool.

The negative aspects can be summarized as follows:

- The maximum actuation force must be limited to protect the internal mechanism of the amplified piezo-stack, and this limit decreases with increasing temperature, being $200 \mathrm{~N}$ at $50{ }^{\circ} \mathrm{C}$.

- The chip shear force capability is low because of the limitation in the maximum actuation force.

- The amplified piezo-stack is quite large, being $13 \mathrm{~cm}$ long. 
- An amplifier is always needed to operate the amplified piezo-stack.

- If the damping factor of the amplified piezo-stack actuator is low (i.e., less than $50 \mathrm{Ns} / \mathrm{m}$ ) and the mass of the moving parts of the amplified piezo-stack actuator is large (i.e., greater than $80 \mathrm{~g}$ ), the response presents large oscillations which may cause instability.

- The price of commercially available amplified piezo-stack actuators with diamond structure is currently high, being of the order of 2000 Euros.

In conclusion, this analysis showed that using amplified piezo-stack actuators for the actuation of direct drive servovalves is feasible and can have interesting features, especially in terms of response speed. However, some drawbacks were found, in particular the chip shear force capability is low and the dimensions are large. The cost of amplified piezo-stack actuators is currently high; however, the cost could be reduced in the future by a large-scale production of these actuators.

The positive features found in this study promote future work, which can be focused on experimentally assessing the effects of the hysteresis of the amplified piezo-stack and on studying the implementation of closed loop control systems. It will also be interesting to compute the damping factor of commercially available amplified piezo-stacks, and to study how the geometry can be designed to obtain convenient values of the damping factor.

\section{References}

1. P. Tamburrano, A.R. Plummer, E. Distaso, R. Amirante. Int. J. Fluid Power, 20(1), 5398 (2019).

2. http://www.moog.com/products/servovalves-servo-proportional-valves.html. Accessed on September $1^{\text {st }}, 2017$.

3. P. Tamburrano, A.R. Plummer, E. Distaso, R. Amirante. J. Dyn. Syst. Meas. Control, 141(2), 020801 (2019).

4. P. Tamburrano, R. Amirante, E. Distaso, A.R. Plummer. Energy Procedia, 148, 487-494 (2018).

5. P. Tamburrano, A.R. Plummer, P. De Palma, E. Distaso, R. Amirante. Energies, 13(3), 671 (2020).

6. P. Tamburrano, A.R. Plummer, P. De Palma, E. Distaso, R. Amirante. Energies, 13(9), 2267 (2020).

7. J. Persson, A.R. Plummer, C.R. Bowen, I. Brooks. Design and Modelling of a Novel Servovalve Actuated by a Piezoelectric Ring Bender. In ASME/BATH 2015 Symposium on Fluid Power and Motion Control, October 12-14, 2015, Chicago, Illinois, USA, (2015).

8. D.K. Sangiah, A.R. Plummer, C.R. Bowen, P. Guerrier. Proceedings of the Institution of Mechanical Engineers. Part I: Journal of Systems and Control Engineering, 227(4), 371389 (2013).

9. A. Milecki. Archiwum Technologii Maszyn i Automatyzacji, 26(2), 177-184 (2006).

10. L. Zhu, E. Shiju, X. Zhu, C. Gao. Development of Hydroelectric Servo-Valve Based on Piezoelectric Elements. In 2010 Int. Conf. Mech. Autom. Control Eng., 26-28 June, Wuhan, China (2010).

11. G.M. Cheng, P. Li, Z. Yang, S.J. E, J.F. Liu. Guangxue Jingmi Gongcheng/Optics and Precision Engineering, 13(3), 276-282 (2005).

12. Y.B. Bang, C.S. Joo, K.I. Lee, J.W. Hur, W.K. Lim. Development of a two-stage high speed electrohydraulic servovalve systems using stack-type piezoelectric elements. In 
IEEE/ASME International Conference on Advanced Intelligent Mechatronics (AIM 2003), 20-24 July, Kobe, Japan (2003).

13. Noliac. Available online: http://www.noliac.com/products/actuators/platestacks/. Accessed on September 1 ${ }^{\text {st }}, 2017$.

14. J. E. Lindler, E. H. Anderson. Piezoelectric direct drive servovalve. Smart Structures and Materials 2002: Industrial and Commercial Applications of Smart Structures Technologies, SPIE 4698 (2002).

15. J. Jeon, C. Han, Y. M. Han, S. B. Choi. Smart Materials and Structures, 23(7), 075002 (2014).

16. Matlab \& Simulink. SimscapeTM user's guide R2019a. The MathWorks, Inc. (2019).

17. J. D. Stringer. Hydraulic Systems Analysis: An Introduction (Macmillan Publishers Limited, Palgrave, London, 1976).

18. H. Merritt. Hydraulic Control System. (John Wiley and Sons, Hoboken, NJ, 1967).

19. P. Tamburrano, A. R. Plummer, P. Elliott, W. Morris, S. Page, E. Distaso, R. Amirante, P. De Palma. 2D CFD analysis of servovalve main stage internal leakage. In ASME/BATH 2019 Symposium on Fluid Power and Motion Control, October 7-9, Sarasota, FL, USA (2019).

20. P. Tamburrano, A.R. Plummer, P. Elliott, P. De Palma, E. Distaso, R. AIP Conference Proceedings, 2191(1), 020146 (2019).

21. G. Di Rito. Int. J. Fluid Power, 8(2), 37-46 (2007).

22. M. Borghi, M. Milani, R. Paoluzzi. Int. J. Fluid Power, 6(2), pp. 5-18 (2005).

23. J. Lugowski. Flow force in a hydraulic spool valve. In ASME-JSME-KSME 2019 Joint Fluids Engineering Conference AJKFLUIDS2019, July 28 - August 1, San Francisco, CA, USA (2019). 